\title{
Evaluación del proteinograma de un canino con síndrome de Cushing y proteinuria
}

\author{
Koscinczuk, P.'; Mussart, N.B. ${ }^{2}$; Cainzos, R.P. ${ }^{1}$ \\ ${ }^{1}$ Cátedra de Patología Médica, ${ }^{2}$ Hospital de Clínica, Facultad de Ciencias Veterinarias, Universidad \\ Nacional del Nordeste, Sargento Cabral 2139, Corrientes (3400), Argentina. \\ E-mail: pkoscinczuk@hotmail.com
}

\begin{abstract}
Resumen
Koscinczuk, P.; Mussart, N.B.; Cainzos, R.P.: Evaluación del proteinograma de un canino con síndrome de Cushing y proteinuria. Rev. vet. 26: 2, 151-153, 2015. La albúmina es la proteína más abundante del organismo. En el suero humano existe una pre-albúmina (transtiretina), cuya elevación se relaciona a un aumento de la síntesis mediada por esteroides, a una disminución del catabolismo, o bien a cambios en el estado de hidratación. En este trabajo se describe el proteinograma de un perro con una glomerulopatía asociada a enfermedad de Cushing con proteínas totales de $5,07 \mathrm{~g} / \mathrm{dl}$ y albúmina de $2 \mathrm{~g} / \mathrm{dl}$, con relación albúmina/ globulinas de 0,59. Para la corrida electroforética de las fracciones seroproteicas se utilizó un soporte de acetato de celulosa, buffer de veronal sódico y coloración amidoschwartz, con ulterior transparentización y cuantificación por densitometría. En el ferograma se observó una fracción que corría por delante de la albúmina (7,6\%). Tanto la fracción albúmina $(29,4 \%)$, como las gamma globulinas (31\%) estuvieron disminuidas, en tanto que las globulinas alfa $(14,9 \%)$ y beta $(17 \%)$ se mantuvieron en rangos normales. En la corrida electroforética de orina solamente se observó la fracción albúmina. Dos meses después del diagnóstico inicial, el paciente retornó a la consulta con deshidratación severa y anuria. La urea había aumentado a $168 \mathrm{mg} / \mathrm{dl}$ y la creatinina a $2,70 \mathrm{mg} / \mathrm{dl}$. Ante la complicación con insuficiencia renal, los dueños del animal solicitaron la eutanasia. Con una incidencia entre 44 y $75 \%$, los perros con síndrome de Cushing pueden presentar proteinuria patológica. Ello implica que la albúmina y otras proteínas de bajo peso molecular se pierdan por orina, dejando al descubierto la fracción de pre-albúmina. Si bien hasta el momento se desconoce la importancia clínica de esta fracción, resulta de interés su presentación en un paciente con síndrome de Cushing sin tratamiento, por considerarlo un hallazgo poco frecuente.
\end{abstract}

Palabras clave: perro, glomerulopatía, Cushing, proteinograma, pre-albúmina.

\begin{abstract}
Koscinczuk, P.; Mussart, N.B.; Cainzos, R.P.: Evaluation of the proteinogram from a canine with Cushing's syndrome and proteinuria. Rev. vet. 26: 2, 151-153, 2015. Albumin is the most abundant protein of the organism. In human serum a pre albumin (transthyretin) is mentioned. Its serum increment is related to the augmentation of synthesis mediated by cortisol and its decrease by changes in the hydration state. In this work, we present the results of a proteinogram from a patient with a glomerulopathy associated to Cushing's syndrome with total protein of $5.07 \mathrm{~g} / \mathrm{dl}$ and albumin of $2 \mathrm{~g} / \mathrm{dl}$, with an albumin/globulin ratio of 0.59 . For the electrophoretic proteinogram an acetate cellulose strip was used with sodic veronal buffer and amidoschwartz coloration, rendered transparent and submitted to densitometry. A fraction before albumin (7.6\%) was observed. Both albumin (29.4\%) and gamma globulin fractions $(31 \%)$ were decreased. The alpha $(14.9 \%)$ and beta $(17 \%)$ fractions were between the normal ranges. In the urine electrophoresis only the albumin fraction was present. Two months after the initial diagnose the patient returned to the clinic with a severe dehydration with anuria. In the biochemistry assay, increment of urea $(168 \mathrm{mg} / \mathrm{dl})$ and creatinine $(2.70$ $\mathrm{mg} / \mathrm{dl}$ ) were observed. The owners decided to perform the euthanasia because of the renal complication and general condition of the pet. Cushing's syndrome in dogs could be accompanied by proteinuria with an incidence of 44 and $75 \%$. Albumin and other low molecular
\end{abstract}


weight proteins can be lost with urine, thus making the pre-albumin fraction detectable in serum. The clinical meaning of this fraction is not known yet, but we consider this finding of interest for those patients with Cushing's syndrome.

Key words: dog, glomerulopathy, Cushing, proteinogram, prealbumin.

\section{INTRODUCCIÓN}

La mayoría de las proteínas séricas son sintetizadas en el hígado; solo una pequeña parte -las inmunoglobulinas- son elaboradas en el sistema retículo endotelial ${ }^{5}$. Al ser fácilmente evidenciadas mediante métodos analíticos de rutina, su incorporación a los perfiles diagnósticos aporta información útil para identificar numerosas patologías.

Para sintetizar proteínas en cantidad adecuada, el hígado necesita disponer de aminoácidos de alto valor biológico que, en el caso de los monogástricos, solo pueden obtenerse a partir de la ingesta y con un intestino funcionando correctamente. Muchas patologías son erróneamente consideradas perdedoras de proteínas (parasitosis crónicas, inflamaciones intestinales), cuando lo que en realidad sucede es que el enterocito es incapaz de absorber los aminoácidos. Si bien el hígado es el órgano clave en la síntesis proteica, la hipoproteinemia por hepatitis es posterior a la aparición de otros signos clínicos (ictericia, encefalopatía hepática, coagulopatías) debido a la prolongada vida media de la mayoría de las proteínas ${ }^{3}$.

Finalmente, las proteínas se consumen o pueden perderse. Las pérdidas más frecuentes ocurren por la vía renal ${ }^{8}$, excepto en el caso de patologías dérmicas extendidas como las quemaduras o la sarna, donde la hipoproteinemia discurre asociada a la exudación ${ }^{1}$. En el caso de pérdida renal de albúmina por glomerulopatía, esta fracción es filtrada por los glomérulos y reabsorbida por las células tubulares proximales por endocitosis mediada por receptores. La internalización por endocitosis es seguida de un transporte dentro de los lisosomas y posterior degradación de la albúmina en sus aminoácidos constitutivos. Por lo tanto, la albuminuria puede reflejar tanto alteraciones de la filtración glomerular como anomalías de la reabsorción tubular ${ }^{2}$.

$\mathrm{Si}$ bien las hipoproteinemias se pueden deber a malnutrición, falla en la síntesis o perdida renal, la concentración plasmática no disminuye de igual manera en todas las fracciones. Cuando la síntesis proteica es deficiente, en primer lugar desaparecen las proteínas de más corta vida media. La persistencia de las proteínas en el suero varía desde minutos a semanas. La albúmina, de prolongada vida media, puede persistir hasta 20 días en el perro ${ }^{5}$.

Otras proteínas, como la pre-albúmina (transtiretina), la proteína ligando de retinol y algunos factores de la coagulación, ostentan una vida media muy corta. $\mathrm{Su}$ concentración sanguínea declina rápidamente cuando hay un problema de síntesis, pero estas disminuciones no se detectan en el proteinograma electroforético porque quedan encubiertas por la albúmina que, como vimos, tiene una vida media más larga ${ }^{1}$.

Las proteínas plasmáticas participan en numerosos procesos biológicos, siendo responsables del mantenimiento de la presión oncótica, de la coagulación sanguínea, del transporte plasmático de metabolitos; algunas poseen actividad enzimática y otras operan como anticuerpos. Cuando un paciente sufre deshidratación, las proteínas plasmáticas aumentan como consecuencia de la pérdida relativa de agua. Ello se debe principalmente a la actividad de la albúmina, la proteína más abundante en el suero canino. Para que se observe una disminución sérica de albúmina, la falla hepática o la pérdida renal deben ser sostenidas en el tiempo ${ }^{3}$.

En medicina humana se describe una pre-albúmina o transtiretina, cuyo incremento sérico se relaciona a un aumento de la síntesis mediada por esteroides, a una disminución del catabolismo y a cambios en el estado de hidratación ${ }^{4}$. En este trabajo se describe el proteinograma de un paciente con enfermedad de Cushing asociada a glomerulopatía, en cuyo suero sanguíneo se constató la presencia de una fracción pre-albúmina.

\section{CASO CLÍNICO}

Un paciente canino hembra de raza caniche, de 6 años de edad, acudió a la consulta por aumento de peso, con una redistribución de la grasa abdominal (Figura 1). El manto presentaba piel fina con pocos pelos y de mala calidad. Estos signos clínicos, asociados a una historia de polidipsia y poliuria, orientaron el diagnóstico hacia una posible endocrinopatía.

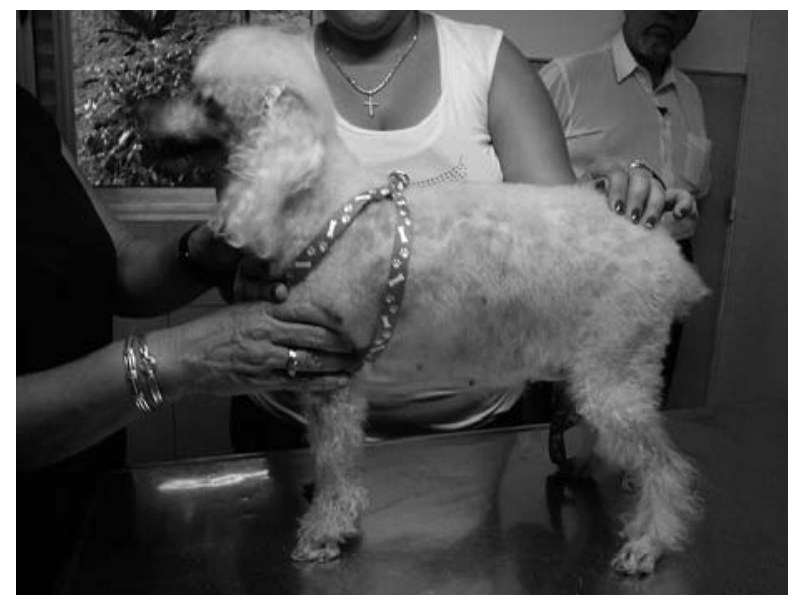

Figura 1. Paciente canina. Nótese el aumento de la cintura pélvica, la atrofia muscular y la pérdida de calidad en el manto piloso. 


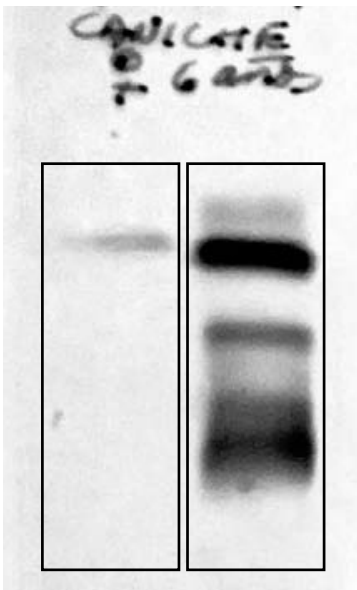

Figura 2. Proteinogramas electroforéticos en orina (izquierda, con una banda de albúmina) y suero sanguíneo (derecha, con una banda de pre-albúmina).

En el análisis bioquímico de la orina matutina se constató hipostenuria (1010) con una microalbuminuria de $19 \mathrm{mg} / \mathrm{dl}$ (por un error técnico no se pudo medir creatinina en orina de la misma muestra). El cortisol plasmático fue de $13,3 \mu \mathrm{g} / \mathrm{dl}$ y el cortisol post estimulación con ACTH fue de $36,3 \mu \mathrm{g} / \mathrm{dl}$. Al momento del diagnostico la urea arrojó un valor sérico de $24 \mathrm{mg} / \mathrm{dl}$ y la creatinina $0,60 \mathrm{mg} / \mathrm{dl}$. El suero no fue reactivo a Leishmania sp. ni Erlichia canis. Inicialmente las proteínas totales fueron de 5,07 g/dl y la albúmina de $2 \mathrm{~g} / \mathrm{dl}$ con una relación albúmina/globulinas de 0,59.

Para la electroforesis de las fracciones seroproteicas se utilizó un soporte de acetato de celulosa, buffer de veronal sódico y coloración amidoschwartz, con ulterior transparentización y cuantificación por densitometría. En ella se observó una fracción que corría por delante de la albúmina $(7,6 \%)$. Tanto la fracción de la albúmina (29,4\%), como la de gamma globulinas (31\%) estuvieron disminuidas, en tanto que las fracciones alfa (14,9\%) y $\beta$ globulinas (17\%) se mantuvieron dentro del rango considerado como normal. En la corrida electroforética de orina solamente se observó la fracción de albúmina (Figura 2).

Dos meses después del diagnostico inicial, el paciente volvió a la consulta con una deshidratación severa y anuria. Al realizarse las pruebas bioquímicas, la urea había aumentado a un valor de $168 \mathrm{mg} / \mathrm{dl}$ y la creatinina a $2,70 \mathrm{mg} / \mathrm{dl}$. Al ser informados sobre las consecuencias de la complicación con insuficiencia renal, los dueños del animal solicitaron la eutanasia, aunque no autorizaron la realización de necropsia.

\section{DISCUSIÓN}

Con una incidencia entre 44 y $75 \%$, el síndrome de Cushing en los perros puede cursar con proteinuria patológica. Entre las hipótesis que explicarían tal proteinuria se describe el aumento de la filtración glomerular, la alteración de la presión intraglomerular con daño de la barrera glomerular y la reducción de la reabsorción tubular ${ }^{7}$. La consecuencia de esta anomalía es la pérdida de albúminas y otras proteínas de bajo peso molecular, la cual se refleja en la disminución de la albúmina plasmática ${ }^{8}$, y justifica la presencia de una albuminuria marcada, acompañada por una hipoalbuminemia ${ }^{6}$.

No obstante, es probable que el hígado haya mantenido parte de su capacidad de síntesis de proteínas, aunque sin llegar a compensar las pérdidas de albúmina sufridas a través de los glomérulos. Quizás por ello en el proteinograma se pudo constatar un aumento de las proteínas de vida media corta, como las que corren en la fracción de pre albúmina ${ }^{1}$.

Es dable destacar que los aumentos séricos de prealbúmina pueden ocurrir como resultado de varios factores, como el efecto de los esteroides anabólicos, los agentes no esteroides anti-inflamatorios, el factor de crecimiento insulínico tipo 1 (IGF-1), la disminución del catabolismo, la falla renal crónica y el daño tubular renal, aunque también pueden deberse a cambios de posición o al estado de hidratación ${ }^{4}$. En el presente caso, tres de estos factores estaban presentes en el paciente: corticoides endógenos aumentados, insuficiencia renal y, probablemente, deshidratación subclínica.

Si bien hasta el momento se desconoce la importancia clínica de la fracción pre-albúmina del suero, resulta de interés su presentación en un paciente con síndrome de Cushing sin tratamiento, por considerarla un hallazgo poco frecuente y también porque el perro desarrolló una insuficiencia renal terminal.

\section{REFERENCIAS}

1. Bertholf R.L. 2014. Proteins and albumin. Lab Med 45: $25-41$.

2. Gorriz JL, Martinez A. 2012. Proteinuria: detection and role in native renal disease progression. Transplant Rev 26: 3-13.

3. Hall EJ, German AJ. 2012. Evaluación laboratorial de la enfermedad hepática. En: Manual de diagnostico de laboratorio en pequeños animales (Villiers E, Blackwood LE, ed), Ediciones "S" (colección BSVA), Madrid, p. 259-291.

4. Johnson AM, Merlini G, Sheldon J, Ichiara K. 2008. Indicaciones clínicas para los ensayos de proteínas plasmáticas: transtiretina (prealbúmina) en inflamación y desnutrición. Acta Bioquím Clín Latinoam 42: 279-288.

5. Kaneko JJ. 1997. Serum proteins and the dysproteinemias. In: Clinical biochemistry of domestic animals (Kaneko JJ, Harvey JW, Bruss ML, Eds.), Academic Press, San Diego, p. 117-138.

6. Mazzi A, Fracassi F, Dondi F, Gentilini F, Famigli P. 2008. Ratio of urinary protein to creatinine and albumin to creatinine in dogs with diabetes mellitus and hyperadrenocorticism. Vet Res Comm 32: 299-301.

7. Smets P, Meyer E, Maddens B, Daminet S. 2010. Cushing's syndrome, glucocorticoids and the kidney. Gen Comp Endocrinol 169: 1-10.

8. Vaden SL. 2011. Glomerular disease. Top Comp Anim Med 26: 128:134. 